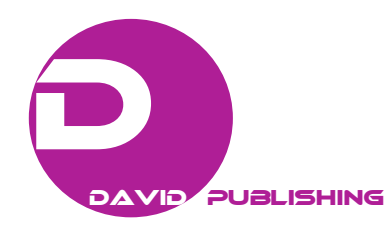

\title{
Study on Hysteretic Bond Mechanisms of Plain Round
}

\section{Bar}

\author{
Cheng Hong ${ }^{1}$ and Hideo Araki ${ }^{2}$ \\ 1. Technology Management Department, Constec Engi, Co., Tokyo 140-0001, Japan \\ 2. Faculty of Engineering, Hiroshima Institute of Technology, Hiroshima 731-5193, Jpan
}

\begin{abstract}
Plain round bars were commonly used as main bars in the design of RC (reinforced concrete) buildings prior to the 1970s. According to previous research investigating the seismic performance of reinforced concrete members constructed with plain round bars, the strength of those members did not reach the calculated flexural strength due to bond slippage of main bars before yielding. It is important, therefore, to investigate the hysteretic bond mechanisms of plain round bars in concrete. In this research, analytical models were proposed to predict hysteretic bond-slip mechanisms between plain round bar and concrete depending on the results of experiments performed by the authors. In addition, the energy absorption capacity and the equivalent viscous damping factors obtained from the experimental results and analytical models are discussed. As a result of comparisons between the experimental data and the analysis models, good agreements were obtained.
\end{abstract}

Key words: Analytical models, energy absorption capacity, equivalent viscous damping factor, epoxy resin injection, plain round bar.

\section{Introduction}

Many existing RC (reinforced concrete) buildings constructed with plain round bars (R-bars) as the main bars have been judged to have high seismic risk in major earthquakes. In order to evaluate the seismic performance of those buildings, many research projects have been conducted. It has been reported that the maximum strength of those RC members with R-bars does not reach the calculated flexural strength. The cause of this low capacity is thought to be because bond slip failure occurs before yielding of the main bars. Because the hysteresis loops of axial load deflection curves were presented as slip type due to slip failure, those members possessed very poor energy absorption capacity [1]. Therefore, bond characteristic between R-bar and concrete is considered an essential factor affecting the seismic performance of existing RC buildings. However, the

Corresponding author: Cheng Hong, Ph.D., research fields: reinforced concrete structure engineering and seismic engineering. E-mail: hong-cheng@cons-hd.co.jp. influence of the bond characteristic above is not considered in the present seismic evaluation for existing RC buildings.

To resist severe earthquakes in Japan, retrofitting and strengthening techniques for existing structures have been in development since 1970. One of the most effective techniques has been epoxy resin injection, which improves the bond strength between the main steel bars and the concrete. The seismic performance of damaged columns repaired with epoxy resin injection has tested in the laboratory of Hiroshima University and it was reported that the flexural strength and ductility of those retrofitted columns were increased [2]. One of the authors also investigated bond strength through pull-out tests using concrete prisms with R-bar injected with epoxy resin. A significant improvement in bond strength was observed in those tests [3].

In this paper, an analytical model of bond hysteresis for R-bars retrofitted with epoxy resin is proposed in order to investigate the seismic performance of the RC members in existing buildings. Following this, the 
validity of the proposed bond-slip model is confirmed in comparison with the observed bond-slip hysteresis. The levels of energy absorption capacity and the equivalent viscous damping factors derived from the experimental data and analytical model are also discussed in this paper.

\section{Experimental Procedure}

\subsection{Test Specimens and Materials}

Each of the specimens used for the pull-out tests was a concrete prism with an R-bar embedded axially. A series of pull-out specimens subjected to monotonic loading are listed in Table 1, those subjected to cyclic loading are listed in Table 2, and details of specimens are illustrated in Fig. 1. In all specimens, the specified concrete strength was $9 \mathrm{MPa}$. The considered variables of the specimens were the diameters of the bar ( $\phi 13$ and $\phi 19)$, the direction of the concrete casting (horizontal and vertical), and the location of the bars (centre and bottom). The prisms were casted as horizontal bars and vertical bars, and the casting direction is also shown in Fig. 1. In addition, concerning the position of the bar due to influence of bleeding in concrete, bond-slip relationship for the location of the bars which were embedded in the top of specimen was extremely different with those which were embedded in the center and bottom. Therefore, in order to ensure accuracy of the monotonic models, experimental date of the specimens with the bars embedded in the center and bottom were only used.
All of the mechanical characteristics of concrete and steel were the same as for previous tests [4].

\subsection{Testing Procedure and Epoxy Resin Injection}

Pull-out loading was subjected to the top end of the embedded bar with a $500 \mathrm{kN}$ capacity center hall jack as shown in Fig. 2. The pull-out load was measured with two types of load cells of $50 \mathrm{kN}$ and $100 \mathrm{kN}$ capacity, in order to properly measure the pull-out force. Slip displacement at the free end of the bar was measured with a displacement transducer instrumented at the end of the prism. In addition, in order to subject the reversal loading in the positive-negative range, a bar was connected to the external bar with a long nut as shown in Fig. 2.

The epoxy resin injection method was low viscous epoxy resin of 100 200 MP which was injected at a very low pressure of $0.06 \mathrm{~N} / \mathrm{mm}^{2}$. Both the details of testing procedures and epoxy resin injection method can refer to the previous study [4].

\section{Hysteretic Bond Characteristic of Plain Round Bars}

Hysteretic bond characteristics between plain round bars and concrete are commonly defined through the constitutive bond-slip relationship. According to the monotonic and cyclic pull-out test before and after retrofitting, the average constitutive bond-slip relationships were obtained by the pull-out load and the slippage was measured at free side of the bar. Low

Table 1 List of specimens subject to monotonic loading.

\begin{tabular}{lllll}
\hline Series of specimens & Number of specimens & Steel & Direction of casting & Location of steel \\
\hline HR13-9 & 5 & & Horizontal & Centre \\
VR13-9 & 3 & $\phi 13$ & Vertical & Horizontal \\
HR13-9-B & 3 & & Horizontal & Bottom \\
\hline HR19-9 & 5 & & Vertical & Centre \\
VR19-9 & 3 & $\phi 19$ & Horizontal & Bottom \\
HR19-9-B & 3 & & & Location of steel \\
\hline Table 2 List of specimens subject to cyclic loading. & & Direction of casting & Centre \\
\hline Series of specimens & Number of specimens & Steel & Horizontal & \\
\hline HR13-9 & 3 & $\phi 13$ & &
\end{tabular}


Monotonic loading

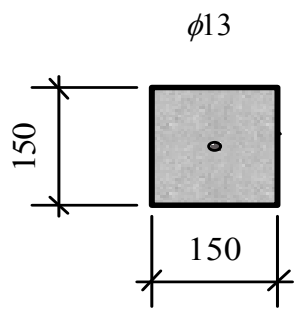

$\phi 13$

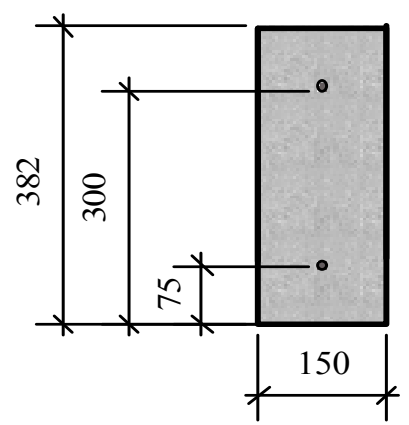

Cyclic loading

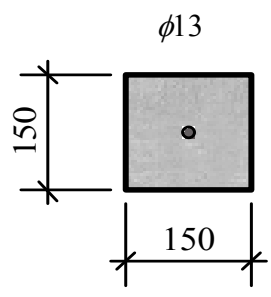

The casting direction

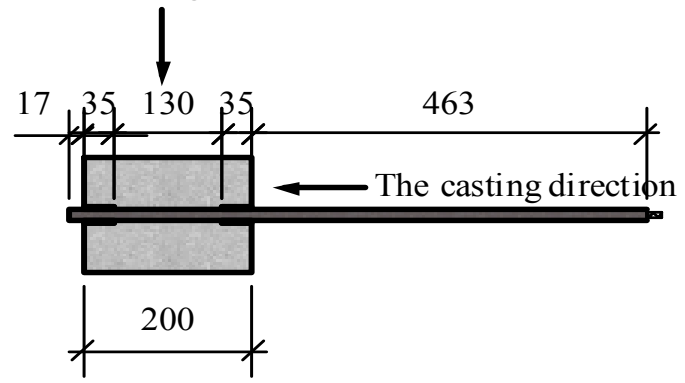

The casting direction
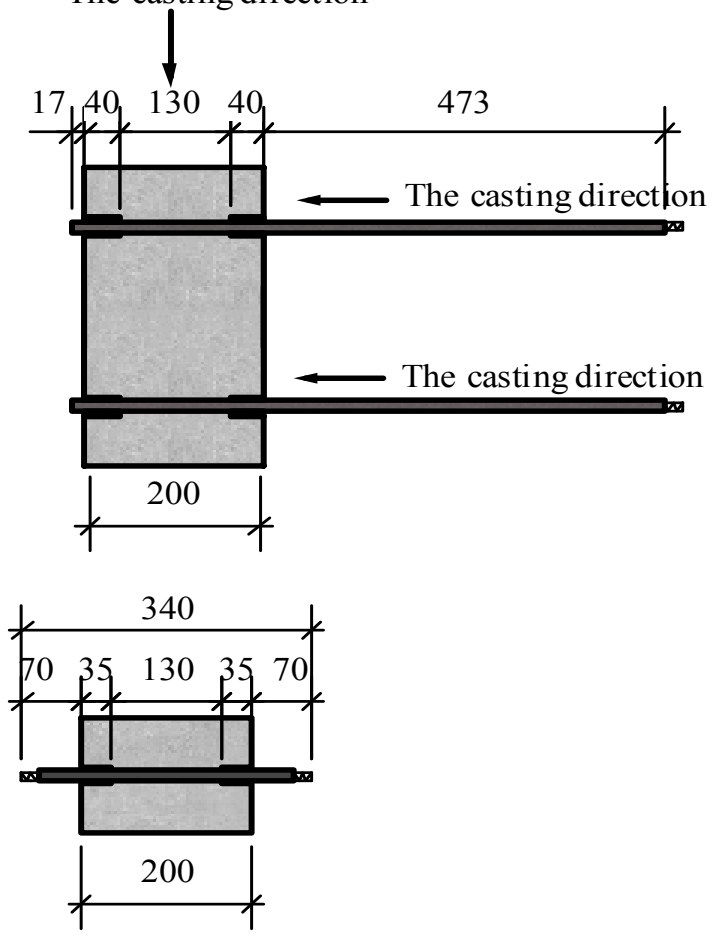

Fig. 1 Details of specimens (units in $\mathbf{m m}$ ).

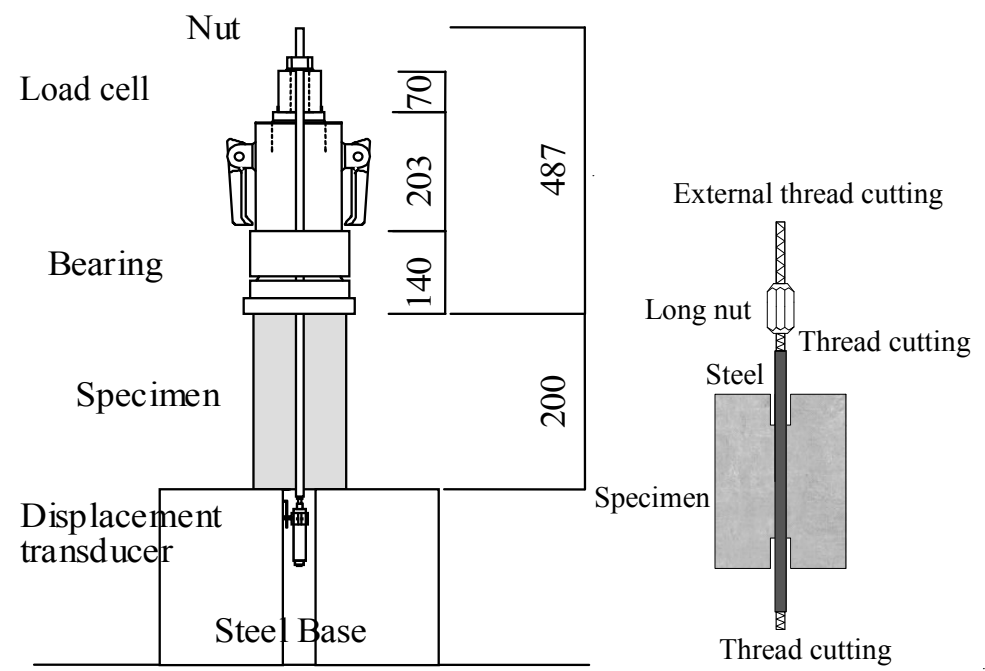

Fig. 2 Details of test apparatus (units in $\mathbf{m m}$ ). 
bond capacity and cyclic degradation phenomena were observed according to the bond-slip relationship of testing specimens without epoxy resin injection. Nevertheless, when testing specimens after retrofitting works, a significant increase effect both in bond capacity and cyclic degradation phenomena was reflected by the comparisons of the corresponding bond-slip relationship. Bond-slip relationships for the cyclic testing specimens before and after retrofitting obtained from the previous studies [4] are shown in Fig. 3.

\section{Fundamental Bond-Slip Model}

According to the proposed bond-slip model without retrofitting in the previous test [3], the new analytical approach to predicting the hysteresis bond-slip relationship of the specimens with retrofitting was also divided into two parts: the envelope curve of monotonic test and the envelope curve of hysteresis loops as shown in Fig. 4. In addition, in this study, all of the hysteretic characteristic parameters in restoring force characteristics were derived from the regression analysis using the experimental data from Tables 1 and 2.

\subsection{Envelope for Monotonic Loading}

The fundamental analytical bond-slip model of retrofitted specimens is shown in Fig. 4. Each point in the monotonic loading envelope was obtained from

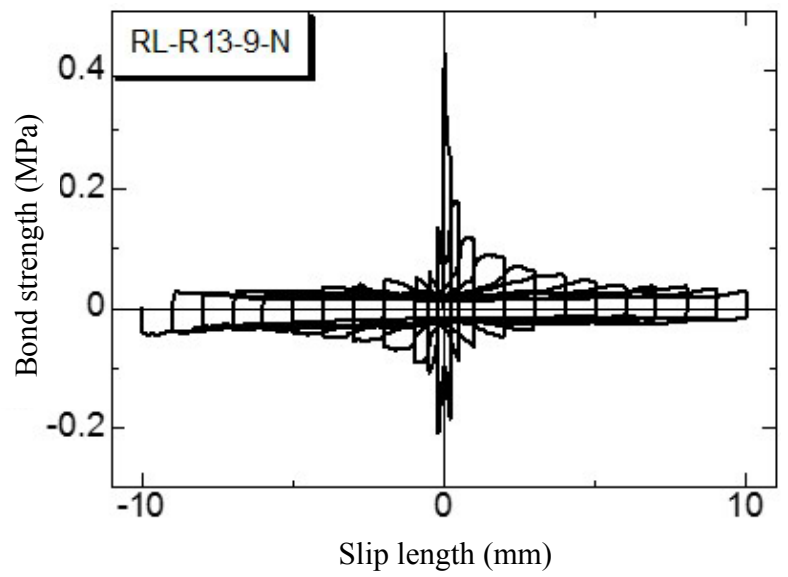

regression analysis using the experimental data of the monotonic pull-out specimens in Table 1. In the figure, Points $\mathrm{A}, \mathrm{C}$ and $\mathrm{D}$ were determined using Point $\mathrm{B}$ $\left(\tau_{\text {Max }}, S_{\text {Max }}\right)$ as the maximum bond strength. $\tau_{\text {Max }}$ is the average maximum bond strength of each series specimens of this experimental study. The experimental value of $S_{\mathrm{Max}}$ ranged from $0 \mathrm{~mm}$ to $0.448 \mathrm{~mm}$, therefore, $S_{\text {Max }}$ was proposed to be $0.2 \mathrm{~mm}$ here.

The envelope composed of the ascending zone shows as Routes $\mathrm{O}-\mathrm{A}$ and $\mathrm{A}-\mathrm{B}$, the descending zone as Route B-C, and the stability zone as Route C-D. The bond strength of envelopes in the ascending zone is presented by Eq. (1):

$$
\begin{aligned}
& S \leq S_{A} \quad \tau=K_{1} \cdot S \\
& S_{A}<S \leq S_{B} \quad \tau=K_{2} \cdot\left(S-S_{A}\right)+\tau_{A}
\end{aligned}
$$

where, the initial stiffness $K_{1}=\tau_{A} / S_{A}=2.375 K_{B}$ $\mathrm{N} / \mathrm{mm}^{3}$ and the second stiffness $K_{2}=\left(\tau_{B}-\tau_{A}\right) /\left(S_{B}-S_{A}\right)$ $=0.083 K_{B} \quad \mathrm{~N} / \mathrm{mm}^{3}$ were obtained from the experimental results of the ascending zone. $S_{A}$ and $\tau_{A}$ are slip displacement and bond strength at Point $\mathrm{A}$ as the intersection between initial incline and second incline, and $S_{B}$ and $\tau_{B}$ are slip displacement and bond strength at Point $\mathrm{B}$ as the maximum bond strength. $K_{B}$ $=\tau_{B} / S_{B}$ is the equivalent stiffness at Point B. Points $\mathrm{A} \sim \mathrm{D}$ are presented as Eq. (2):

$$
\begin{aligned}
& A\left(\tau_{A}=0.95 \tau_{\text {Max }}, S_{A}=0.40 S_{\text {Max }}\right), B\left(\tau_{B}=\tau_{\text {Max }}, S_{B}=S_{\text {Max }}\right) \\
& C\left(\tau_{C}=0.50 \tau_{\text {Max }}, S_{C}=5 \mathrm{~mm}\right), D\left(\tau_{D}=0.50 \tau_{\text {Max }}, S_{D}>5 \mathrm{~mm}\right)
\end{aligned}
$$

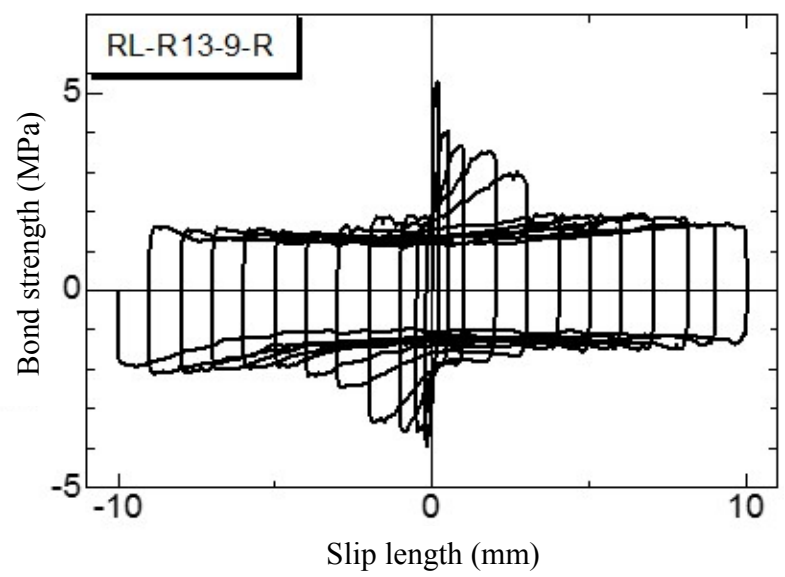

Fig. 3 Bond-slip relationship for cyclic testing before and after retrofitting works. 


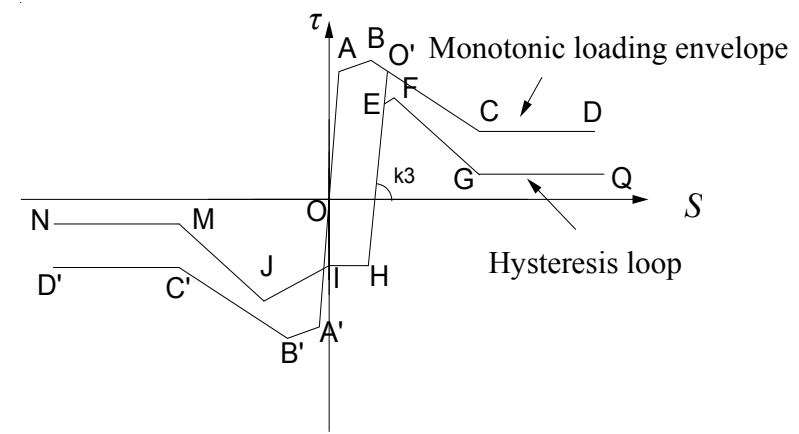

Fig. 4 Fundamental bond-slip model.

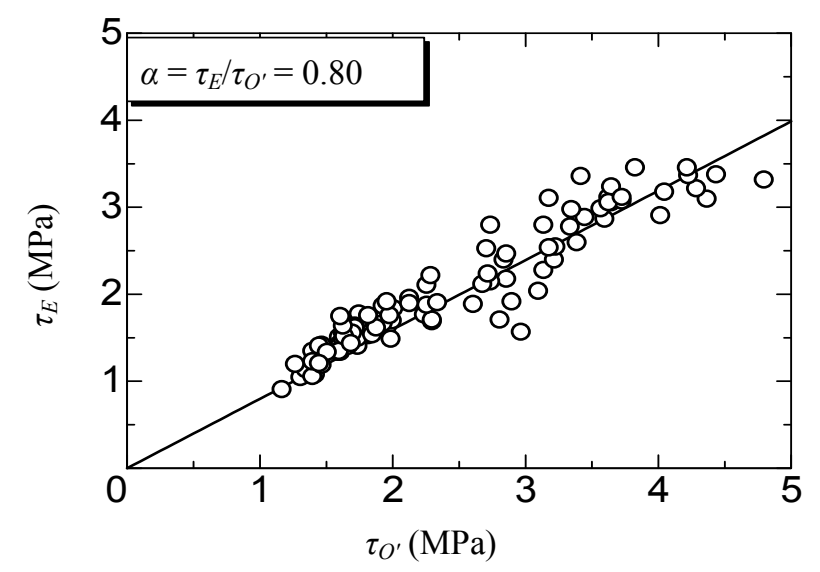

Fig. 5 Regression analysis of parameter $\alpha$.

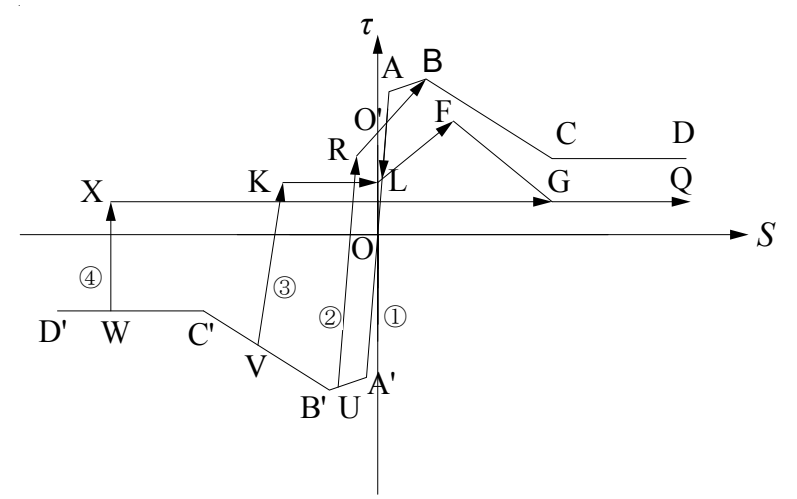

Fig. 6 Load reversed at O-A.

\subsection{Envelope for Cyclic Loading}

The proposed envelope under reversal load is also shown in Fig. 4 based on the experimental data of the specimens shown in Table 2. After cyclic loading, when the load was reversed in Path $\mathrm{O}^{\prime}-\mathrm{H}$, the bond strength reached Point E. Point $\mathrm{E}$ is represented by Eq. (3) using the coordinate of Point $\mathrm{O}^{\prime}$.

$$
E\left(\tau_{E}=\alpha \tau_{O^{\prime}}, S_{E}=S_{O^{\prime}}-(1-\alpha) \tau_{O^{\prime}} / K_{3}\right)
$$

where, $\alpha$ in Eq. (3) is a reduction factor $\left(\alpha=\tau_{E} / \tau_{O^{\prime}}\right)$ to the bond strength of the previous loading where $\alpha$ is assumed to be 0.80 referred to Fig. 5. $K_{3}=\mid \tau_{O^{\prime}}-$ $\tau_{H}|/| S_{O^{\prime}}-\tau_{H} \mid=54.3 \mathrm{~N} / \mathrm{mm}^{3}$ was obtained from experimental data shown in Table 2.

The bond strength was assumed to increase to Point $\mathrm{F}$ and decrease to Point $\mathrm{G}$ through Path F-G. After Point G, the bond stress is constant. Points F, G and $\mathrm{Q}$ are shown by Eq. (4):

$$
\begin{aligned}
& F\left(\tau_{F}=0.89 \tau_{o}, S_{F}=1.13 S_{o}\right), G\left(\tau_{G}=0.22 \tau_{\text {Max }}, S_{G}=5 \mathrm{~mm}\right) \\
& Q\left(\tau_{Q}=0.22 \tau_{\text {Max }}, S_{Q}>5 \mathrm{~mm}\right)
\end{aligned}
$$

The Envelope J-M-N on the negative side is symmetrical to F-G-Q.

\section{Hysteretic Rules of Cyclic Loading}

In the previous study, Morita et.al. [5] and Verderame et al. [6, 7] proposed the hysteresis rules of deformed bars and R-bars. Referring to these proposed hysteresis bond-slip models, the analytical hysteretic bond-slip models for R-bars when unloaded from monotonic loading curve in different zone can be determined as following.

\subsection{Unloaded from Ascending Zone (O-A)}

When the load was reversed from Point $\mathrm{O}^{\prime}$ at Path $\mathrm{O}-\mathrm{A}$, the load-deflection relationship is elastic, and hysteresis rules are shown in Fig. 6.

The path is: $\mathrm{O}^{\prime}-\mathrm{A}^{\prime}-\mathrm{B}^{\prime}-\mathrm{C}^{\prime}-\mathrm{D}^{\prime}$. Assuming that the load was reversed at Point $\mathrm{O}^{\prime \prime}$ (Points $\mathrm{A}^{\prime}, \mathrm{U}, \mathrm{V}$ and $\mathrm{W}$ in Fig. 6), the following bond-slip curve can be divided into four cases, as follows:

(1) $S_{A^{\prime}} \leqq S_{O^{\prime \prime}}<S_{A}$. When the load was in path A'-O-A, load-deflection relationship is elastic;

(2) $S_{B^{\prime}} \leqq S_{O^{\prime \prime}}<S_{A^{\prime}}$. When the load was reversed from Point $U$ at Path $\mathrm{B}^{\prime}-\mathrm{A}^{\prime}$, the bond-slip path was U-R-B-C-D. Point R is represented by Eq. (5) using the coordinate of Point $\mathrm{U}$;

$$
R\left(\tau_{R}=-\beta \tau_{U}, S_{R}=S_{U}-(1+\beta) \tau_{U} / K_{1}\right)
$$

where, $\beta=\left|\tau_{H} / \tau_{O^{\prime}}\right|$ is a parameter defined as the reduction of 0.62 referred to Fig. 7; 
(3) $S_{C^{\prime}} \leqq S_{O^{\prime \prime}}<S_{B^{\prime}}$. When the load was reversed from Point $\mathrm{V}$ at Path $\mathrm{B}^{\prime}-\mathrm{C}^{\prime}$, the stiffness is the same as stiffness $K_{1}$ up to Point K. The bond strength of Point $\mathrm{K}$ is consisting until slip deflection approaches to the previous Point L. The bond-slip path in this case was V-K-L-F-G-Q and Points K and F are shown in Eq. (6) using the coordinate of Point V:

$$
\begin{aligned}
& K\left(\tau_{K}=-\beta \tau_{V}, S_{K}=S_{V}-(1+\beta) \tau_{V} / K_{3}\right) \\
& L\left(\tau_{L}=\tau_{K}, S_{L}=0\right) \\
& F\left(\tau_{F}=0.89 \tau_{V}, S_{F}=1.13 S_{V}\right)
\end{aligned}
$$

(4) $S_{O^{\prime \prime}}<S_{C^{\prime}}$. When the load was reversed from a point between $\mathrm{C}^{\prime}$ and $\mathrm{D}^{\prime}$, the bond strength was assumed constant until the ultimate slip deflection. The bond-slip path was W-X-G-Q and Point $\mathrm{X}$ is shown in Eq. (7) using the coordinate of Point W:

$$
X\left(\tau_{X}=0.22 \tau_{\text {Max }}, S_{X}=S_{W}\right)
$$

\subsection{Unloaded from Ascending Zone (A-B)}

The analytical model when the load was reversed from Point $\mathrm{O}^{\prime}$ in the Path A-B is shown in Fig. 8. The

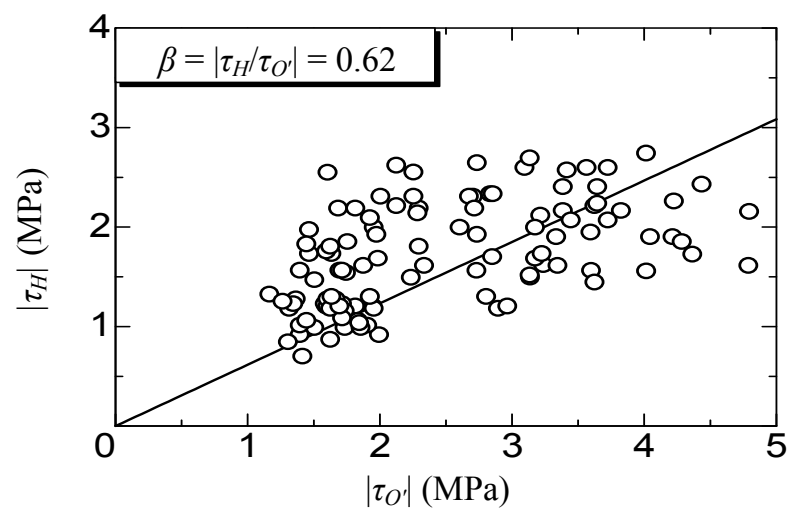

Fig. 7 Regression analysis of parameter $\beta$.

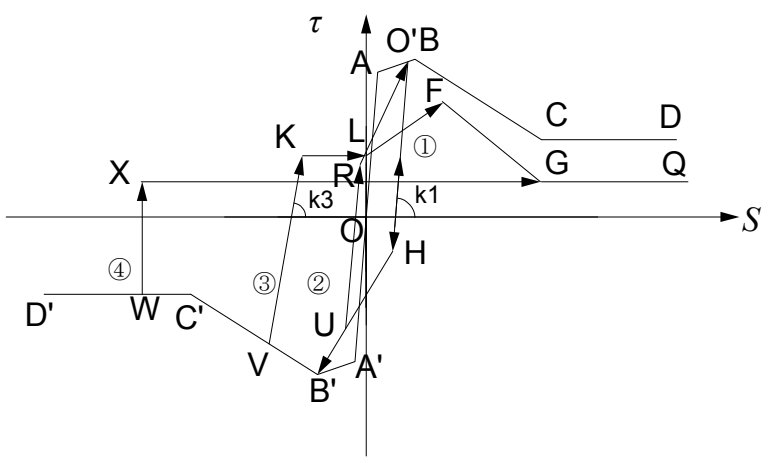

Fig. 8 Load reversed at A-B. stiffness was assumed to be $K_{1}$ for Point $\mathrm{H}$. After Point $\mathrm{H}$, the strength returns to Point $\mathrm{B}^{\prime}$. On the negative side, the bond-slip envelope followed the monotonic loading envelope.

The path is: $\mathrm{O}^{\prime}-\mathrm{H}-\mathrm{B}^{\prime}-\mathrm{C}^{\prime}-\mathrm{D}^{\prime}$. Assuming that the load was reversed at Point $\mathrm{O}^{\prime \prime}$, the following bond-slip curve can also be divided into four cases, as follows:

(1) $S_{O^{\prime \prime}} \geqq S_{H}$. The bond-slip path followed a linear unloading line with the stiffness $K_{1}$ and reached the monotonic loading envelope on the positive side;

(2) $S_{B^{\prime}} \leqq S_{O^{\prime \prime}}<S_{H}$. When the load was reversed at Point $U$ in Path $B^{\prime}-H$, the bond-slip path was U-R-B-C-D. Point R is represented by Eq. (8) using the coordinate of the previous Point $\mathrm{U}$ :

$$
R\left(\tau_{R}=-\beta \tau_{U}, S_{R}=S_{U}-(1+\beta) \tau_{U} / K_{1}\right)
$$

(3) $S_{C^{\prime}} \leqq S_{O^{\prime \prime}}<S_{B}$. When the load was reversed at Point V in Path $\mathrm{B}^{\prime}-\mathrm{C}^{\prime}$, the bond-slip path was the same as the previously mentioned Case 3 in Section 5.1;

(4) $S_{O^{\prime \prime}}<S_{C^{\prime}}$. When the load was reversed at a point in the constant strength zone $\mathrm{C}^{\prime}$ - $\mathrm{D}^{\prime}$, the bond-slip relationship was the same as the previous mentioned Case 4 in Section 5.1.

\subsection{Unloaded from Descending Zone (B-C)}

The analytical model when the load was reversed in Path B-C is shown in Fig. 9. When the load was reversed at Point $\mathrm{O}^{\prime}$, bond strength decreased with stiffness $K_{3}$ and reached Point $\mathrm{H}$ on the opposite side. Point $\mathrm{H}$ is represented by Eq. (9) using the coordinate of Point $\mathrm{O}^{\prime}$ :

$$
H\left(\tau_{H}=-\beta \tau_{O^{\prime}}, S_{H}=S_{O^{\prime}}-(1+\beta) \tau_{O^{\prime}} / K_{3}\right)
$$

Slip deflection reached Point I while bond strength was constant. When the slip deflection reached the negative area, the bond strength increased up to Point $\mathrm{J}$. After Point J, the strength reached Point M. Finally, bond strength became constant. When the load was reversed in Path H-I-J-M-N, the following bond-slip curve could also be divided into four parts:

(1) $S_{H} \leqq S_{O^{\prime \prime}}<S_{O^{\prime}}$. When the load was reversed from a point at Path $\mathrm{O}^{\prime}-\mathrm{H}$, the bond-slip path followed a linear unloading path with stiffness $K_{3}$ and reached 
the monotonic loading envelope on the positive side;

(2) $0 \leqq S_{O^{\prime \prime}}<S_{H}$. When the load was reversed from Point $U$ at Path $\mathrm{I}-\mathrm{H}$, the bond-slip path was U-R-E-F-G-Q. Point R is shown in Eq. (10) using the coordinate of Point $\mathrm{U}$ :

$$
R\left(\tau_{R}=-\beta \tau_{U}, S_{R}=S_{U}-(1+\beta) \tau_{U} / K_{3}\right)
$$

(3) $S_{M} \leqq S_{O^{\prime \prime}}<0$. When the load was reversed from Point $\mathrm{V}$ at Path M-I, the bond-slip path was V-K-L-E-F-G-Q. Point K was shown in Eq. (11) using the coordinate of Point $\mathrm{V}$ :

$$
\begin{aligned}
& K\left(\tau_{K}=-\beta \tau_{V}, S_{K}=S_{V}-(1+\beta) \tau_{V} / K_{3}\right) \\
& L\left(\tau_{L}=\tau_{K}, S_{L}=0\right)
\end{aligned}
$$

however, if $\tau_{K}=-\beta \tau_{V} \leq 0.22 \tau_{\mathrm{Max}}$, value of $\tau_{K}$ was assumed to be $0.22 \tau_{B}$;

(4) $S_{O^{\prime \prime}}<S_{M}$. When the load was reversed in the large slip length area, the bond-slip relationship was the same as the previously mentioned Case 4 in Section 5.1.

\subsection{Unloaded from Stability Zone (C-D)}

The analytical model when the load was reversed in Path C-D or G-Q (Fig. 10). The bond strength decreased without change of slip deflection and reached the constant strength $\tau=-0.22 \tau_{\text {Max }}$.

\section{Comparisons with Test Results and Proposed Model}

Comparisons between the test results of $\phi 13$ and $\phi 19$ specimens and the proposed bond-slip model with a small slip deflection $(0 \sim 1 \mathrm{~mm})$ and large slip deflection $(0 \sim 10 \mathrm{~mm})$ are shown in Fig. 11. The bond-slip model provided approximate agreement with the test results. However, some differences could be found due to parameters $\alpha$ and $\beta$, which were influenced by the number of loading cycles.

\section{Discussions on Seismic Performance}

Energy absorption capacity, and equivalent viscous damping factor versus slip length are shown in Figs. 12 and 13, respectively. The analytical results are also inserted into Figs. 12 and 13. The analytical model results depended on the average maximum bond strength of each series.

As shown in Fig. 12, the energy absorption capacity of the specimens with retrofitting for $\phi 13$ bar was significantly higher than that of $\phi 19$.

As shown in Fig. 13, the equivalent viscous damping factor in each cycle was also nearly the same. The value was in the range of about $40 \%$ to $50 \%$.

The analytical results also provided good agreement with the experimental results. However, due to the influence of the progressive deterioration of the bond characteristics when the number of loading cycles increases, some differences between the test results and the predicted results are found.

\section{Conclusions}

This research aims to build a proper model in order to assess seismic capacity and deformational behaviors of existing RC buildings with R-bars under epoxy resin injection. Based on the experimental date, hysteretic bond-slip models have been proposed, and the following conclusions can be made:

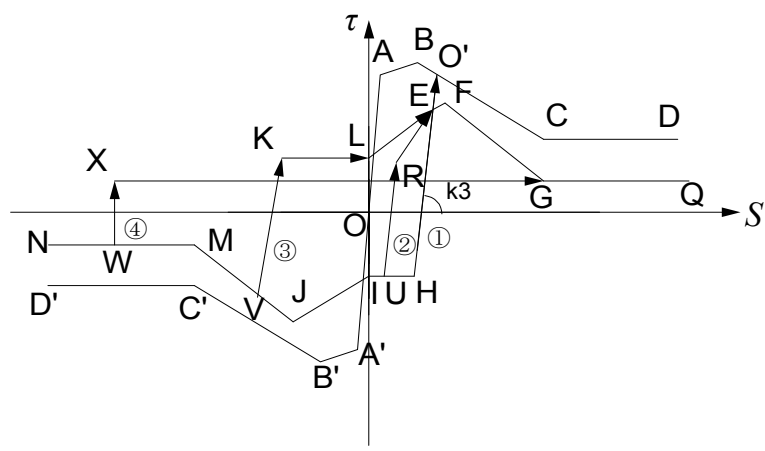

Fig. 9 Load reversed at B-C.

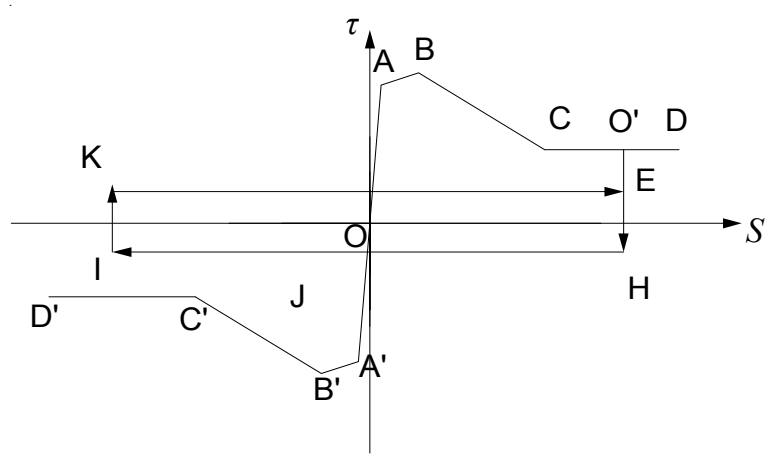

Fig. 10 Load reversed at C-D. 


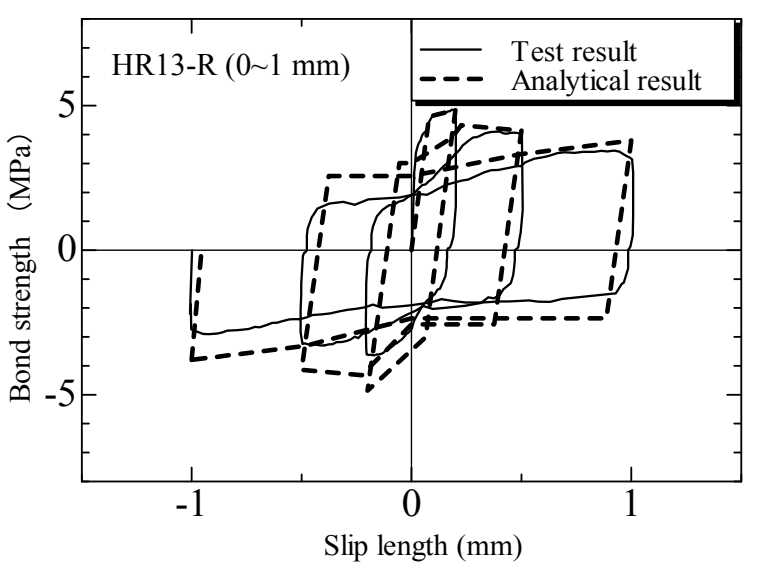

(a)

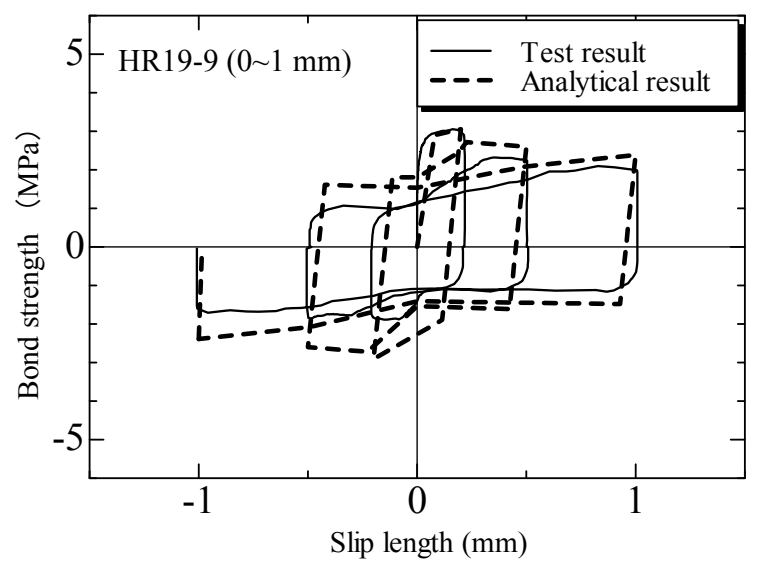

(c)

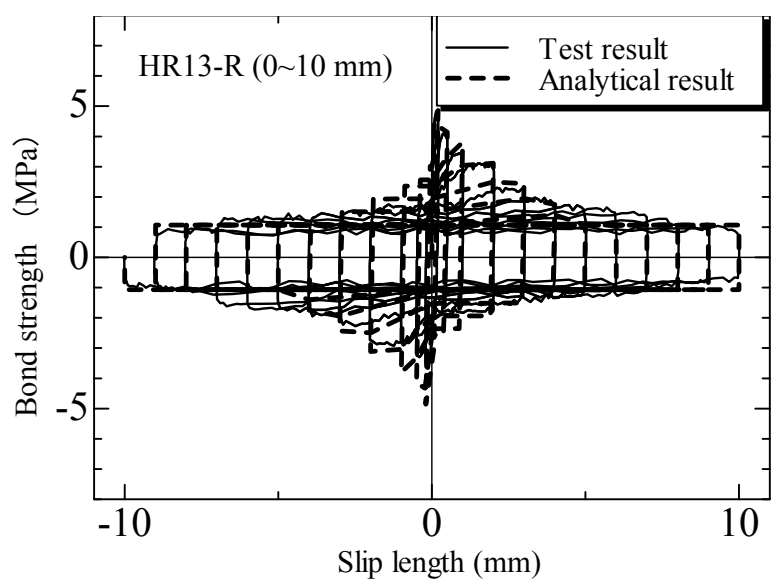

(b)

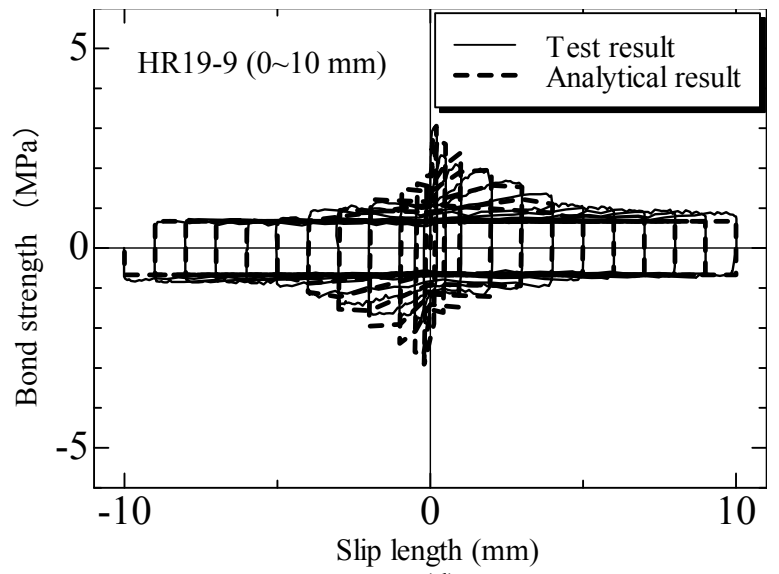

(d)

Fig. 11 Comparisons between the testing results and the proposed model of bond-slip relationship: (a) HR 13-9 (0 1 mm); (b) HR 13-9 (0 10 mm); (c) HR 19-9 (0 1 mm); (d) HR 19-9 (0 10 mm).

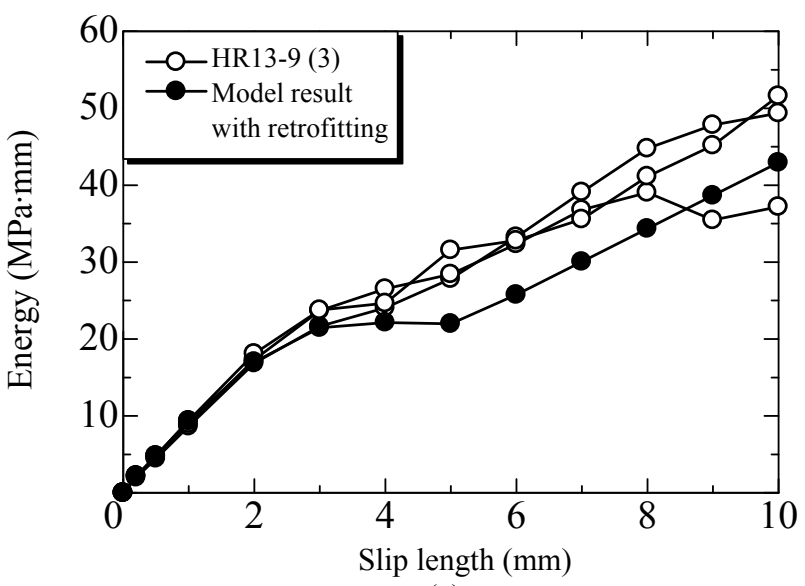

(a)

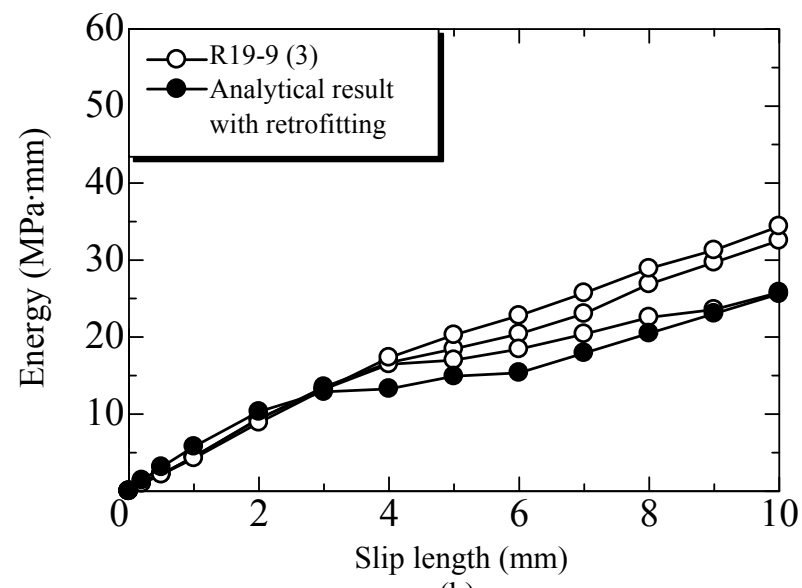

(b)

Fig. 12 Comparisons between the testing results and the proposed model of energy absorption capacity: (a) HR 13-9; (b) HR 19-9. 

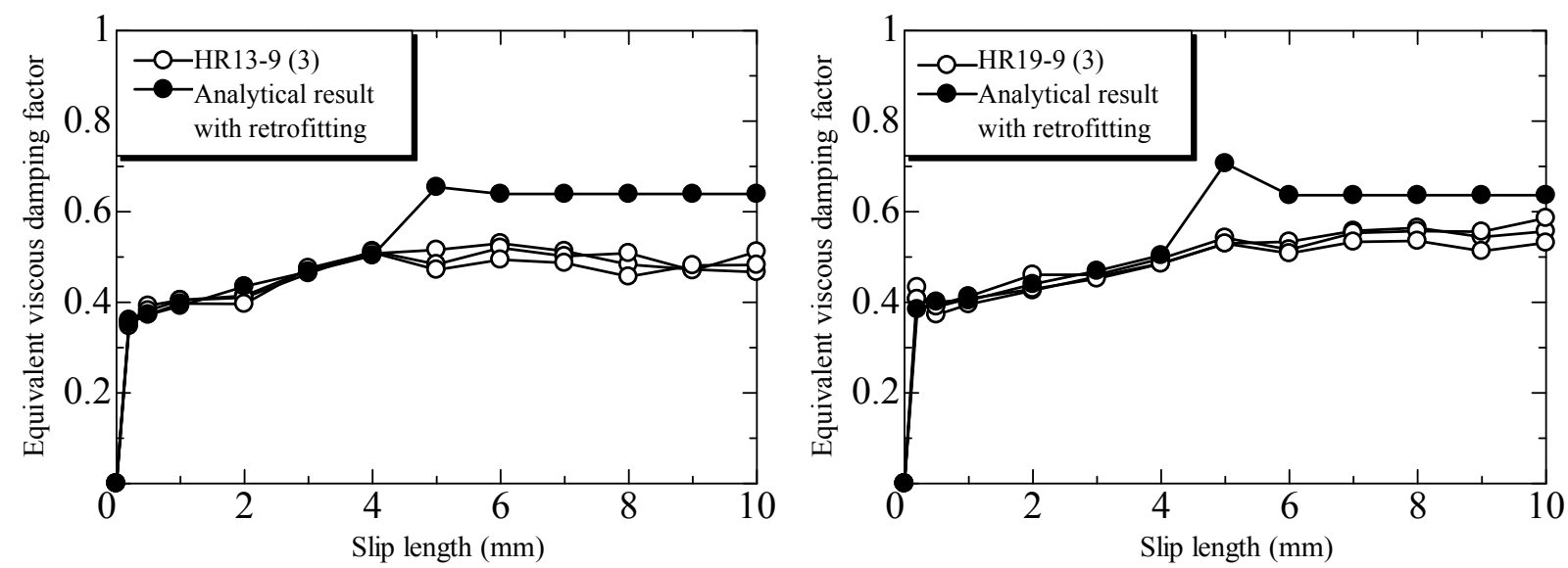

Fig. 13 Comparisons between the testing results and the proposed model of equivalent viscous damping factor: (a) HR 13-9; (b) HR 19-9.

(1) All of the proposed hysteretic bond-slip models were defined by the regression analysis of the experimental date, and composed of monotonic curve and cyclic curve. In addition, corresponding to the different conditions of unloading and reloading, various hysteretic bond-slip models were discussed in this paper;

(2) The results of previous experimental bond investigations indicate that all the characteristic points related to the shape of models, which were expressed proportionally to the average maximum bond strength of each series specimens;

(3) The proposed models provided good agreement with the experimental results by the discussion on both the bond-slip relationship and the seismic performance. Therefore, the proposed models are considered to be useful in analytical predictions of deformation and seismic capacity of those existing structures. However, due to influence of the progressive bond deterioration during increase of the cyclic loading number, the irregular parts can be also observed in the figures. Therefore, in order to improve and prefect the hysteretic bond models for the plain round bars, it is necessary to consider more and more empirical validations in future ;

(4) Seismic performance of the specimens for $\phi 13$ was extremely greater than those specimens for $\phi 19$ by means of the comparisons of energy absorption capacity. However, the equivalent viscous damping factor in each cycle was nearly the same.

\section{Acknowledgments}

This research has been supported by the Japan Ministry of Education, Culture, Sports, Science and Technology under Grant-in-Aid No. 21360268. The materials and technology for epoxy resin injection has been supplied by SG Engineering Corporation. The authors would like to thank the staff and graduate students of the Structural Earthquake Engineering Lab of Hiroshima University.

\section{References}

[1] Taniguchi, H., Yasojima, A., Araki, H. 2008. "Seismic performance of Reinforced Concrete Beams with Low Strength Concrete." In Proceeding of 14th Word Conference on Earthquake Engineering, Paper ID-05-03-0034.

[2] Araki, H., and Izaki, S. 2012. "Seismic Performance of Damaged Low Strength Concrete Column Repaired by Epoxy Resin Injection." Journal of Architectural Institute of Japan 18 (38): 181-6.

[3] Araki, H., and Kagawa, J. 2010. "Bond Strength of Plain Round Bars Repaired by Epoxy Resin Injection." Presented at the 34th International Association for Bridge and Structural Engineering Symposium, Italy, Venice.

[4] Hong, C., and Araki, H. 2012. "Bond-Slip Relationship between Low strength Concrete and Plain Round Bar under Reversal Loadings." In Proceedings of 15th World Conference on Earthquake Engineering, Paper ID: 1072.

[5] Morita, S., and Kaku, T. 1974. "Local Bond Stress-Slip 
under Repeated Loading." Presented at Theme IV, Rilem Symposium, Prague.

[6] Verderame, G. M., Ricci, P., De Carlo, G., and Manfredi, G. 2009. "Cyclic Bond Behaviour of Plain Bars. Part I: Experimental Investigation." Construction and Building
Materials 34: 3499-511.

[7] Verderame, G. M., Ricci, P, De Carlo, G., and Manfredi, G. 2009. "Cyclic Bond Behaviour of Plain Bars. Part II: Analytical Investigation." Construction and Building Materials 34: 3512-22 